\title{
Analysis on Main Difficulties Faced by Chinese Macro Economy under Financial Crisis and Countermeasures
}

\author{
Hongzheng Wang \\ Shenzhen Polytechnic, Shenzhen Guangdong, 518055, China
}

Key words: Financial crisis, Macro economy, Difficulty.

\begin{abstract}
Subprime crisis of Wall Street, USA triggered global crisis and the economy of the whole world was impacted seriously. This crisis not only involved financial field, but also influenced the real economy of the whole society. China has entered WTO and become an entirety with close connection to the world economy. Therefore, China was also influenced greatly in this crisis. Regarding how to take decisive measures under the current financial crisis and make Chinese macro economy develop healthily and orderly, we can analyze the development status of Chinese economy, study main difficulties faced currently and put forward corresponding countermeasures.
\end{abstract}

\section{Introduction}

Faced with great impact of global financial crisis, various countries in the world have taken a series of measures to save the economy. In terms of the current influence of financial crisis on China, the overall financial economy of China was not impacted seriously due to its important control over the field of financial investment. However, the real economy of China was influenced greatly. Therefore, macro-control means should be taken.

\section{Various difficulties in Chinese economy brought by financial crisis}

\section{Problems caused by trade surplus}

Under heavy losses of the world economy, various countries in the world analyzed the reason of its occurrence. A prominent problem in the whole East Asian region is the imbalance of international trade and China is the region with the most serious influence. It will produce some trade frictions invisibly and influence economic development. RMB appreciation after financial crisis resulted in the increase of export and foreign exchange reserve in China. However, huge foreign exchange reserve is faced with a series of problems caused by constant depreciation of US dollar. This problem is very serious and influencing the direct interest of China.

Even so, Chinese export trade has still made great contributions to the economy of the whole society. In 2009, China became the first largest exporting country and the second largest trading country in the world. The share and position of China in international trade cannot be neglected. However, Chinese trade export mainly centers on mid- and low-end products in terms of international division of labor. Chinese foreign trade scale has increased rapidly over the years, but its quality and benefit are not very high. Products with core competitiveness are lacking. Such situation of "high input and low earning” will hardly continue for a long term. The living standard of the whole people will be influenced inevitably.

\section{Low anti-risk capability factor of many foreign trade enterprises in China}

With the outbreak of crisis, Chinese government has taken a series of measures to resist some external risks. However, some foreign trade enterprises had low competitiveness and poor ability of resisting 
risks under the situation of weak demands of the whole international market, increase of production cost and RMB appreciation. Many enterprises had a series of problems and even went bankrupt finally. China is a large trading country. Export slowdown will inevitably cause the solvency of many enterprises. This will increase the employment pressure of China and cause some unstable factors to the society. Therefore, we must improve the ability of foreign trade enterprises to resist risks and improve their competitiveness as soon as possible.

\section{Uncertainty of credit flow}

The flow of credit funds in China mainly has three directions - investment, real estate and financial asset. Investment is the leading credit flow in the whole economy. However, with the end of investment, whether investment has actually driven the increase of domestic demand cannot be verified. If demands are not driven, capital chain will break. This has undoubted hindered the aftereffect of economic growth. With constant emergence of real estate market, many investors turn to real estate, which will inevitably cause bubble economy of real estate market. Improper national control over real estate will inevitably influence the quality of such credit. The financial field of credit flow will also cause a bubble phenomenon of future economy because financial field will push the price of the whole asset to the high position. How to control the flow of credit and reach an equilibrium state is also a difficult problem faced by Chinese economic regulation and control.

\section{Fiscal policy has positive effects but meanwhile will cause some problems.}

The Chinese government plays an important role in financial crisis. The government strengthens macro control over the whole economy with full use of fiscal policy and monetary policy. The improvement of government investment strength will inevitably promote rapid development of the whole national economy. Private economy and some small- and medium-sized enterprises will inevitably be influenced. As national economy has fund allowance of the state and meanwhile economic development is protected, great benefits brought by great increase of national economy will be easily plundered by some corrupt people, thus making the masses unable to benefit from economic growth. This will undoubtedly produce certain influence on the development of private economy, disturb the whole market economic order and seriously go against the principle of equality and justice of market economic development. Moreover, most funds of many state-owned enterprises flow to real estate market and financial market, thus aggravating market economic bubble and containing great risks. If national macro regulation and control policies cannot bring actual benefits to the public and are utilized by few lawbreakers, it will not simply be a problem at economic level but will evolve into a more serious problem at social level.

\section{The prevention of Chinese economy is still a difficult problem.}

Government investment is an important factor driving economic recovery under this financial crisis. Large-scale investment belongs to government action and has obvious emergent behavior. We are worried about the bearing capacity of the government after effective control of the whole economy. Follow-up problem of some enterprises and some private investment will be faced in the long term. If government action stops, a series of chain reactions will be caused and a greater economic crisis might break out. Interference behavior of the government can promote industrial recovery. However, excess production capacity will be caused meanwhile. Enterprises will also enter into the period of profit difficulty. Investment behavior of the government has promoted the upturn of the whole economy, but can not necessarily secure benefits for enterprises. According to the specific situation, enterprises gaining financial support have improved economic situation. However, the export industry is still in the state of continuous deterioration.

Negative growth of consumption is also an aspect with precaution. The contribution rate of Chinese consumption to economic growth is still very low. It is very difficult to drive economic growth simply with investment. The government should analyze some factors restraining consumption objectively and make corresponding countermeasures rapidly. 


\section{Suggestions on macro economic regulation and control policies under financial crisis}

Financial crisis brings existing crisis to the world and meanwhile contains opportunities. This poses a great challenge to Chinese economic development. If Chinese government can cope with this financial crisis very well, it will certainly lay a foundation for China resisting external financial risks. Chinese government has made appropriate and timely response in this crisis management. The government improves healthy and orderly operation of the whole financial system by reducing deposit and loan interest rate and deposit reserve ratio. This is a successful act in Chinese macro regulation and control policy. However, how to give play to macro regulation and control better is still an important and arduous issue faced by Chinese government.

\section{Domestic demand is the basic power of Chinese economic growth.}

It is found through investigation that Chinese economic development has a serious problem, i.e. excess production capacity. Since the entry of China into economic globalization organization, its economic development has taken the internationalized path. China has been closely connected to the world economy. Most products produced by Chinese enterprises involve export trade. Economic development mode relies too much on the international market. When economic order in international market is influenced by some factors, the whole economy will get into a very passive situation, thus causing continuous downturn of the whole economy. To solve such status, it is required to change economic growth pattern and gradually turn export products to the domestic market, thus expanding domestic demand, stimulating consumption and driving economic growth.

Currently, China is still a great agricultural country with weak agricultural economic foundation, extensive growth of agricultural economy and inadequate capital investment. Therefore, we should strengthen agricultural input, change extensive mode of agricultural economic growth to intensive mode, improve income level of peasants and drive the development of rural industrial economy. Central and western regions of China have a huge market. The state should strengthen the development of western tourism resources and attract more domestic and overseas tourists, thus driving the rapid development of the whole western economy. China has taken some subsidiary measures to stimulate domestic demand, such as home appliance going rural with subsidy, purchasing of agricultural mechanical equipment with subsidy and rural greenhouse cultivation with subsidy. These measures have not only stimulated consumption, but also driven economic growth.

\section{Increase enterprise investment and promote export}

According to the scope of influence of financial crisis, it is difficult to expand domestic demand in a short time for the driving of Chinese economic growth based on export. Enterprises still have a large market overseas. The government should issue relevant policies to strengthen enterprise investment, especially some small- and medium-sized enterprises, so as to improve employment rate and the consumption level of residents. The government can adjust the whole foreign trade structure with tax policy and bank loan so that enterprises can raise fund smoothly, the real economy can get huge savings fund and enterprise capacity can reach a reasonable level, thus strengthening the confidence of enterprise operators.

\section{Improve social security system}

Social security career of China has achieved long-term development. However, existing social security system still has many problems which directly hinder the development of Chinese socialist market economy. Chinese social security system is still at a low level and the coverage of security programs is not wide enough. People do not have the sense of security and therefore deposit money constantly and accumulate capital for a rainy day. Based on the difference of social system, western countries have complete social security system and people do not have fear of attacks from behind or deposit money in order to guarantee basic life. They enjoy life more and their consumption concept is more advanced. Therefore, complete social security system is a guarantee of the whole national 
economic development. Only with constant improvement of social security system can we drive domestic demand better and promote economic growth.

\section{Take positive fiscal policy and appropriately slack monetary policy.}

Positive fiscal policy can promote economic growth and optimize industrial structure through the expansion of fiscal expenditure. According to the influence of financial crisis on China, the government plays an important role in the whole economic regulation and control. The government can expand domestic demand by reducing and exempting taxes, reducing value added tax of enterprises and expanding disposable income of residents and through expenditure action. The strengthening of guarantee for low-income groups by the government through expenditure can not only increase disposable income of residents, but also promote social stability and unity. Investment allowance of the government is an effective measure for economic intervention, which can guide the investment direction of enterprises. While facing instability factors of international environment, Chinese government has appropriately adjusted monetary policy, adopted relatively loose monetary policy, lowered deposit reserve ratio continuously for multiple times, reduced loan cost of enterprises and encouraged residents for reasonable consumption. These measures have made some significant achievements.

\section{Conclusion}

Faced with severe challenge of financial crisis, Chinese government has taken timely and effective emergency measures. Chinese economic development will inevitably be influenced by the world economy. Economic development is influenced by multiple aspects. However, as long as we take preventive measures well and adjust policies in time according to the general trend of world economic development, Chinese economy will play a standing role and develop steadily and healthily in the big wave of world economy.

\section{References}

[1] Zeng Xiuling. Brief Analysis on Macro Economic Dilemma and Macro Policy Selection of China under Financial Crisis. Journal of Northeast University of Electric Power, 2010 (3).

[2] Liu Wei. Chinese Macro Economic Trend and Macro Regulation and Control Policies under International Financial Crisis Background. Journal of Chongqing Technology and Business University: West Forum, 2009 (4).

[3] Ren Kangyu. Challenges Faced by Chinese Macro Economy in Post Financial Crisis Era, Inner Mongolia Financial Research, 2010 (5).

[4] Wang Zhengping. Thinking on Countermeasures of Chinese Macro Economic Regulation and Control under Global Financial Crisis. Journal of Shenzhen University (Humanities and Social Sciences), 2009 (1).

[5] Ba Shusong. New Financial Development and Financial Policy Trend of Chinese Macro Economy in International Financial Crisis. Capital Market, 2009 (6). 